\title{
Serum Thyroglobulin Levels in Preterm Infants with and without the Respiratory Distress Syndrome. I. Cord Blood Study
}

\author{
J. H. KOK, W. H. H. TEGELAERS, AND J. J. M. DE VIJLDER \\ Department of Neonatology and Department of Pediatrics, Academic Medical Center, University of Amsterdam, \\ Amsterdam, The Netherlands
}

\begin{abstract}
Cord serum levels of thyroglobulin (Tg) and thyroid stimulating hormone (TSH) in 147 term and preterm infants were related to gestation age, birth weight, respiratory distress syndrome (RDS), and several perinatal factors by means of multiple linear regression analysis. None of the perinatal factors influenced $\mathrm{Tg}$ and $\mathrm{TSH}$ cord serum levels. However, in infants who developed RDS, Tg and TSH cord serum levels differed significantly from values in infants who did not develop this syndrome. In RDS infants, significantly higher $\mathrm{Tg}$ values were found. $\mathrm{Tg}$ cord serum levels increased with birth weight in the "average" RDS infant (i.e. infants with birth weights according to the 50th percentile of the growth chart for their gestation age), while these levels decreased in the "average" nonRDS infant. In RDS infants TSH cord serum levels increased with increasing birth weight, while these levels did not vary in non-RDS infants. Although Tg and TSH cord serum levels in RDS infants increased during gestation, no correlation between $\mathrm{Tg}$ and TSH cord serum levels could be demonstrated. There was no correlation between $\mathrm{Tg}$ and TSH cord serum levels in non-RDS infants. Since we found a clear correlation between $\mathbf{T g}$ cord serum levels and gestation age, but no correlation between $\mathrm{Tg}$ and TSH cord serum levels, we suggest that other phenomena are responsible for the high Tg levels such as organ immaturity. (Pediatr Res 20: 996-1000, 1986)
\end{abstract}

\section{Abbreviations}

$\mathrm{Tg}$, thyroglobulin

TSH, thyroid stimulating hormone

BW, birth weight

GA, gestation age

RDS, respiratory distress syndrome

hTg, human thyroid glands

RIA, radioimmunoassay

Cord serum $\mathrm{Tg}$ levels in term infants are higher than in adults (1). Preterm infants have higher $\mathrm{Tg}$ cord serum levels than term infants, and there is a negative relationship of $\mathrm{Tg}$ cord serum levels with gestation age (2). In adults $\mathrm{Tg}$ synthesis and secretion are under control of TSH (3). TSH cord serum levels show a slight decrease (4) or do not vary (5) with GA, and no correlation between $\mathrm{Tg}$ and $\mathrm{TSH}$ cord serum levels has been demonstrated

Received April 10, 1985: accepted May 29, 1986.

Correspondence J. J. M. de Vijlder, Academic Medical Center, Meibergdreef 9, 1105 AZ Amsterdam, The Netherlands.

Supported by the Praeventie Fonds.
$(2,6)$. Apparently, in the fetal period, Tg cord serum levels are not under control of TSH. The decrease of Tg cord serum levels with gestation age may indicate that the thyroid gland becomes less permeable (to $\mathrm{Tg}$ ) with increasing maturation (2).

It is generally accepted that the development of the RDS reflects a delayed maturation of the lungs. Thyroid hormones are known to stimulate lung maturation in animals $(7,8)$. Thyroid hormones in cord serum increase with GA (9). Lower thyroid hormone levels in cord serum have been demonstrated in infants who develop RDS (10-12) than in those who do not. Since $\mathrm{Tg}$ cord serum levels may indicate the degree of maturation of the thyroid gland, we advance the hypothesis that in RDS infants higher $\mathrm{Tg}$ cord serum levels will be found. Herein we evaluate this idea. Furthermore we investigate the influence on $\mathrm{Tg}$ cord serum levels of several perinatal factors which may influence the maturation. The relationship between $\mathrm{TSH}$ and $\mathrm{Tg}$ cord serum levels is studied as well.

\section{PATIENTS AND METHODS}

Patients. Cord blood samples were obtained from 147 infants (123 preterm and 24 term infants) admitted into the neonatal department because of prematurity or low birth weight for GA. BW varied from 675 to $3640 \mathrm{~g}$; GA varied from 25 to $40 \mathrm{wk}$ of gestation. GA was calculated from the mother's last menstrual period. In case of doubt GA was estimated from the Dubowitz score (13).

Each neonate was evaluated for the idiopathic RDS. There were 117 infants without RDS and 30 infants who developed the syndrome. The diagnosis of RDS was made using the criteria of Usher (14). In addition to the following perinatal factors were recorded for each patient: treatment with tocolytics (non-RDS 36 , RDS nine), premature rupture of the membranes (non-RDS 25, RDS two), betamethasone treatment (non-RDS 28, RDS 11), the mode of delivery: caesarean section (non-RDS 20, RDS three) or vaginal delivery (non-RDS 97, RDS 27), sex (85 boys: nonRDS 66, RDS 19; and 62 girls: non-RDS 51, RDS 11), neonatal asphyxia: Apgar score of less than 7 (non-RDS nine, RDS nine), multiple birth (non-RDS 14, RDS 11).

Methods. Tg levels were measured by a double antibody RIA method. The preparation and assessment of purity of isolated $\mathrm{Tg}$ from $\mathrm{hTg}$, obtained after autopsy, were conducted as described by Ket et al. (2). $\left.{ }^{125} \mathrm{I}\right] \mathrm{Tg}$ was obtained after iodination of $10 \mu \mathrm{g}$ hTg with $1 \mathrm{mCi}^{125} \mathrm{I}^{-}(15)$. Rabbit antihuman $\mathrm{Tg}$ was used at a dilution of $1: 75,000$. As second antibody an excess of donkey antirabbit $\gamma$-globulin serum (Wellcome, Beckenham, England) was used at a dilution of $1: 24$. The human sera were diluted $1: 10$ with goat serum sodium phosphate-salt buffer $(1: 10) \mathrm{mix}-$ ture. The composition of the sodium phosphate-salt buffer was $3.5 \mathrm{mM}$ sodium phosphate, $0.15 \mathrm{M} \mathrm{NaCl}$ and $0.25 \mathrm{M}$ EDTA, 
$\mathrm{pH}$ 7.5. The standard line was obtained by adding $\mathrm{Tg}$ to the goat serum sodium phosphate-salt buffer $(1: 10)$. The addition of pasturized human plasma containing $5 \mathrm{ng} \mathrm{Tg} / \mathrm{ml}$ in the ratio 1:10 to the assay tubes did not affect the $\mathrm{Tg}$ standard curve. Each sample was determined in triplicate with two controls without added anti-Tg. Nonspecific binding was less than $2 \%$ in the presence of approximately $1 \mu \mathrm{g} \mathrm{Tg}$.

The lower limit of detection was $3 \mathrm{ng} \mathrm{Tg} / \mathrm{ml}$ diluted serum, the highest value found was $170 \mathrm{ng} \mathrm{Tg} / \mathrm{ml}$ diluted serum. This means that 30 to $1700 \mathrm{ng} \mathrm{Tg} / \mathrm{ml}$ serum can be measured accurately. Recovery of $\mathrm{hTg}$ added to diluted serum averaged $100 \pm$ $13 \%(n=9)$ in the range of 13 to $90 \mathrm{ng} / \mathrm{ml}$ of $\mathrm{Tg}$, with an absolute deviation of about $3 \mathrm{ng} / \mathrm{ml}$. After dilution of two sera $(1: 10,1: 20,1: 40)$ containing 510 and $740 \mathrm{ng} \mathrm{Tg} / \mathrm{ml}$, respectively, the measured $\mathrm{Tg}$ concentrations were within $2.5 \%$ of the expected values. Dilution of serum (1:10) containing $55 \mathrm{ng} \mathrm{Tg} /$ $\mathrm{ml}$ (measured in undiluted serum) gave a value of $6.2 \mathrm{ng} / \mathrm{ml}$ diluted serum.

The intraassay coefficient of variation calculated according to Van Herle et al. (1) was $4.4 \%$ on the basis of values ranging from 3.7 to $13.7 \mathrm{ng} / \mathrm{ml}$ in diluted sera $(n=27)$, and $5.3 \%$ on the basis of values ranging from 16.8 to $63.9 \mathrm{ng} / \mathrm{ml}$ in 15 diluted sera. The interassay coefficient of variation did not exceed $12 \%$ for values ranging from 11 to $169 \mathrm{ng} / \mathrm{ml}$ obtained on 20 diluted serum samples.

Measurements of anti-Tg autoantibodies were performed with the help of thymune T-kits of Burroughs (Wellcome Ned BV), Weesp, The Netherlands.

TSH determinations were performed by RIA as described by Odell et al. (16). The lower limit of detection was $0.5 \mathrm{mU} / \mathrm{liter}$. The intraassay coefficients of variation of values ranging from 2 to $8 \mathrm{mU} /$ liter did not exceed $6 \%$, and those of more than $8 \mathrm{mU} /$ liter did not exceed $13 \%$. The interassay coefficient of variation was approximately $10 \%$ for values ranging from 1.6 to $27 \mathrm{mU} /$ liter. All determinations were done in duplicate.

Statistical analysis of the results included analysis of variance and application of the multiple linear regression model (17) after logarithmic transformation (see Appendix). For correlation analysis Pearsons' correlation coefficient was used (18).

\section{RESULTS}

$T g$. Tg was measured in all cord blood samples. One hundred samples were examined for the presence of maternal anti- $\mathrm{Tg}$ autoantibodies which can be transferred via the placenta. Autoantibodies were not detected in any of these samples anti-Tg autoantibodies were detectable. This leads to a $95 \%$ confidence limit of $3 \%$ for the probability of anti-Tg autoantibodies in a single sample.

All $\mathrm{Tg}$ values measured were used in the regression analysis. In this analysis it is necessary to test whether the regression of $\log \mathrm{Tg}$ on BW and GA was parallel for each perinatal factor (see Appendix). The hypothesis could be accepted for all investigated perinatal factors, but not for the respiratory distress syndrome $\left(\mathrm{F}=14.09_{\mathrm{df} 2.141}, p<0.01\right)$. Therefore the regression analysis was performed separately in non-RDS $(n=117)$ and RDS $(n=30)$ infants.

Non-RDS infants. $\log \mathrm{Tg}$ in non-RDS infants was found to depend on BW and GA only. Insertion of the other perinatal factors did not improve the regression equation (none of the perinatal factors tested had a $p$ value of less than 0.05 ).

The regression equation was found to be:

$$
\begin{gathered}
\log \mathrm{Tg}=2.86+0.152 \mathrm{BW}-0.031 \mathrm{GA} \pm 0.25 \\
(r=0.31, p<0.01)(\mathrm{BW} \text { in } \mathrm{kg}, \mathrm{GA} \text { in } w k)
\end{gathered}
$$

As can be seen from the regression coefficients and their associated SEs (Table 1), log Tg increases significantly with increasing $\mathrm{BW}$ when GA is constant, and decreases significantly with in- creasing GA when BW is constant. In Figure 1 we show the relationship between $\mathrm{Tg}$ and $\mathrm{BW}$ for different gestation ages. This illustrates the differences in the height of the $\mathrm{Tg}$ cord serum levels between the lighter and the heavier infants with the same GA. Since BW increases during normal development of the fetus, we calculated the estimated Tg values in "average" infants, i.e. infants with BW according to the 50th percentile of the Kloostermans' growth chart (19) for several different GA. The broken line, constructed from the estimated $\mathrm{Tg}$ values, represents $\mathrm{Tg}$ in the "average" infant in the last trimester of gestation.

$R D S$ infants. For RDS infants the regression equation was found to be:

$$
\begin{gathered}
\log \mathrm{Tg}=-1.06-0.836 \mathrm{BW}+0.155 \mathrm{GA} \pm 0.30 \\
(r=0.61, p<0.01)(\mathrm{BW} \text { in } \mathrm{kg}, \mathrm{GA} \text { in wk). }
\end{gathered}
$$

Insertion of the perinatal factors did not improve the regression equation. The SEs of the regression coefficients are given in Table 1. It can be seen that in RDS infants log $\mathrm{Tg}$ decreases significantly with increasing BW when GA is constant, and increases significantly with increasing GA when BW is constant. Thus the dependence of $\log \mathrm{Tg}$ on GA and BW in RDS infants is the opposite of that for non-RDS infants. Figure 2 shows the results.

Table 2 summarizes the relevant mean data of $\mathrm{Tg}$ values in the infants subdivided according to their gestation ages; an extra column is added showing the estimated $\log \mathrm{Tg}$ values (i.e. values computed from the regression equation).

$T S H$. As with Tg, TSH cord serum levels in RDS infants showed a different dependence on BW and GA compared with non-RDS infants $\left(\mathrm{F}=3.30_{\mathrm{df} 2,141}, p<0.05\right)$. Therefore the regression analysis was performed separately for RDS and nonRDS infants. Neither in the non-RDS nor in the RDS infants did any of the perinatal factors improve the regression equations. The following regression equation was found for non-RDS infants:

$$
\begin{gathered}
\log \mathrm{TSH}=0.49-0.077 \mathrm{BW}+0.016 \mathrm{GA} \pm 0.27 \\
(r=0.15, p=0.20)(\mathrm{BW} \text { in } \mathrm{kg}, \mathrm{GA} \text { in wk }) .
\end{gathered}
$$

As can be seen from the regression coefficients and their associated SEs (Table 1), the contributions of BW and GA are not significant and can be ignored. This implies that in non-RDS infants no dependence on either BW or GA is demonstrated.

The equation for RDS infants was:

$$
\begin{gathered}
\log \mathrm{TSH}=-0.43+0.29 \mathrm{BW}+0.027 \mathrm{GA} \pm 0.33 \\
(r=0.41, p=0.10)(\mathrm{BW} \text { in } \mathrm{kg}, \mathrm{GA} \text { in wk). }
\end{gathered}
$$

\begin{tabular}{|c|c|c|c|c|c|c|}
\hline & \multicolumn{3}{|c|}{ BW } & \multicolumn{3}{|c|}{ GA } \\
\hline & $b_{1}$ & SE & $p$ & $\mathrm{~b}_{2}$ & SE & $p$ \\
\hline $\log \mathrm{Tg}$ & & & & & & \\
\hline non-RDS & 0.152 & 0.055 & $<0.01$ & -0.031 & 0.009 & $<0.01$ \\
\hline RDS & -0.836 & 0.238 & $<0.01$ & 0.155 & 0.040 & $<0.001$ \\
\hline Log TSH & & & & & & \\
\hline non-RDS & -0.077 & 0.059 & NS & 0.016 & 0.010 & NS \\
\hline RDS & 0.290 & 0.262 & NS & 0.027 & 0.044 & NS \\
\hline
\end{tabular}

As can be seen from the regression coefficients and their associated SEs (Table 1), either of the two factors (GA or BW) can be omitted from the model. However, after omitting GA a specific

Table 1. Results of the regression equations of multiple linear regression analysis for $\log T g$ and $\log T S H$ in non-RDS and RDS infants*

* The regression coefficients $\left(b_{1}\right.$ and $\left.b_{2}\right)$ and their associated SEs are given with their $p$ values (BW in $\mathrm{kg}, \mathrm{GA}$ in wk). 


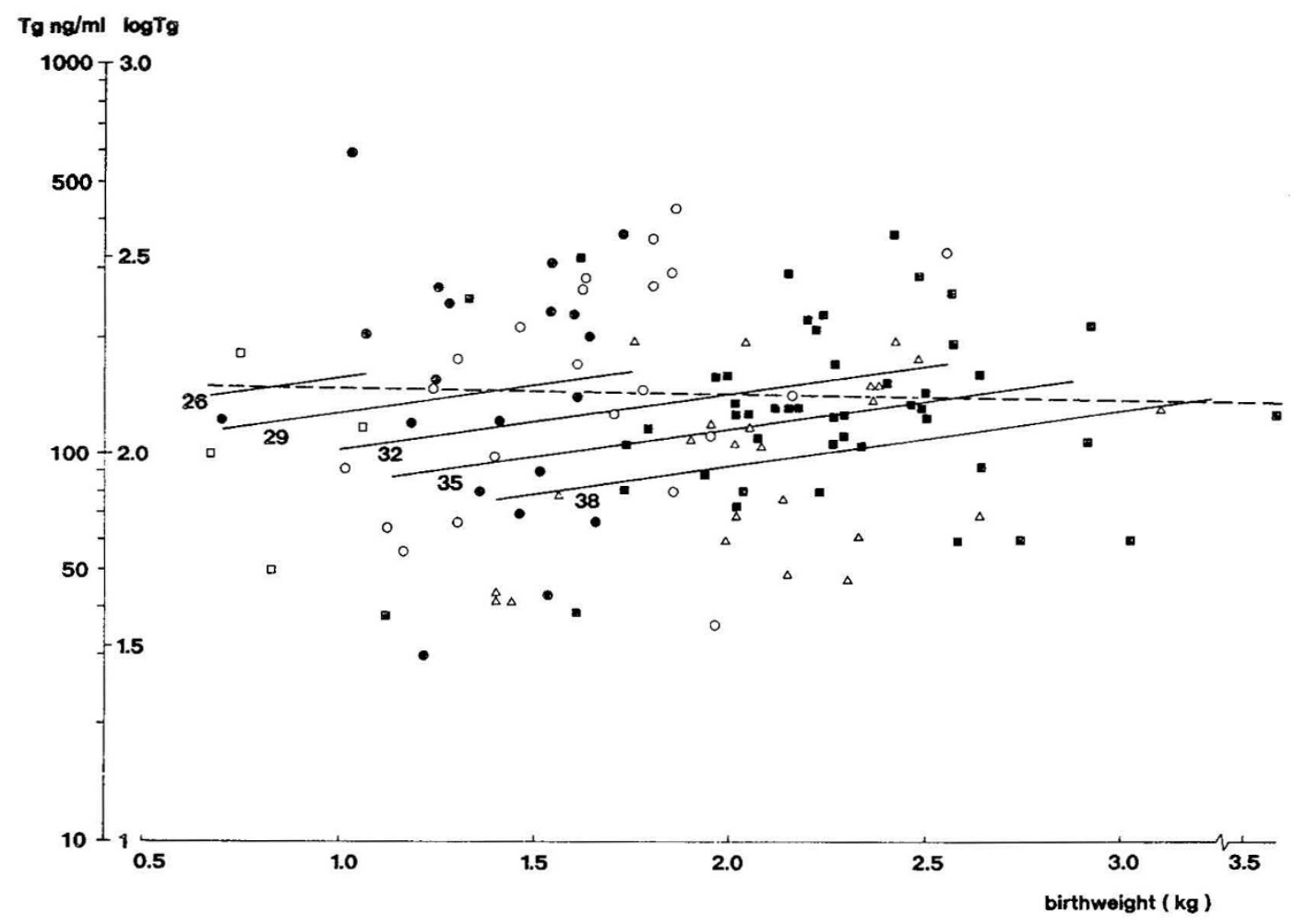

Fig. 1. Cord serum Tg values of non-RDS infants. The Tg values are indicated by symbols according to the gestation age ( $\square, 25-26-27$ wk; 28-29-30 wk; O 31-32-33 wk;, $34-35-36 \mathrm{wk} ; \Delta, 37-38-39-40 \mathrm{wk}$ ). Regression lines (solid lines) of Tg cord serum values on BW for different $\mathrm{GA}$ are given according to: $\log \mathrm{Tg}=2.86+0.152 \mathrm{BW}-0.031 \mathrm{GA} \pm 0.25, r=0.31, p<0.01$. The broken line indicates log Tg of the "average" non-RDS infant (see text).

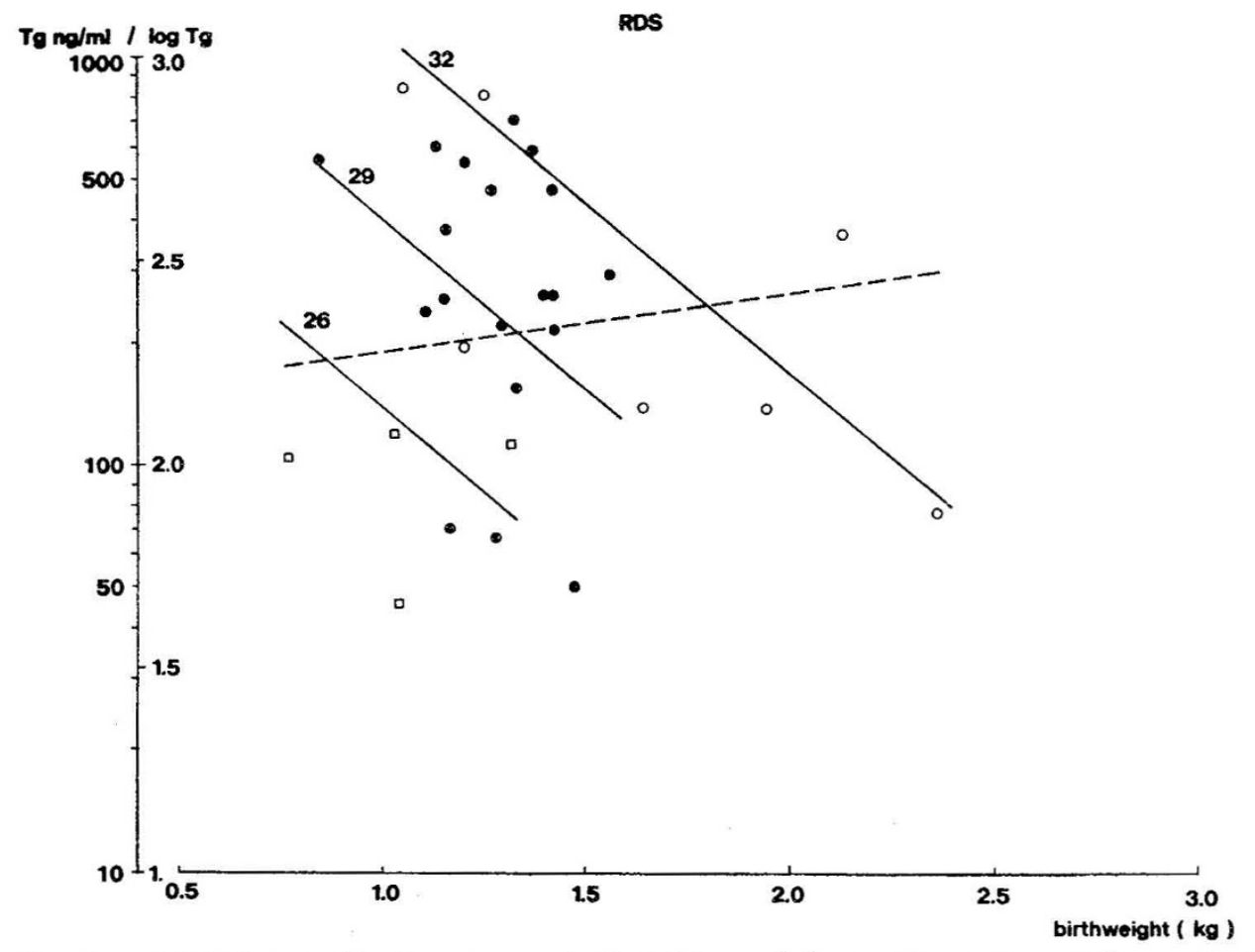

Fig. 2. Cord serum Tg values of RDS infants. The Tg values are indicated by symbols according to the gestation age ( $\square, 25-26-27$ wk; $\bullet$, 2829-30 wk; O 31-32-33-34 wk). Regression lines (solid lines) of $\mathrm{Tg}$ cord serum values on BW for different GA are given according to: log Tg = $-1.06-0.836 \mathrm{BW}+0.155 \mathrm{GA} \pm 0.30, r=0.61, p<0.01$. The broken line indicates $\log \mathrm{Tg}$ of the "average" RDS infant (see text).

effect of BW is found, according to:

$$
\begin{gathered}
\log \mathrm{TSH}=0.21+0.407 \mathrm{BW} \pm 0.33 \\
(r=0.39, p<0.05)(\mathrm{BW} \text { in } \mathrm{kg})
\end{gathered}
$$

No specific effect for GA alone was demonstrated $(r=0.36,0.05$ $<p<0.10$ )

4a) Figure 3 shows the TSH values plotted against BW in both RDS and non-RDS infants. There is a significant increase in TSH values with birthweight in RDS infants $(p<0.05)$. In non- 
Table 2. Mean BW, GA, and $\log T g$, and $\log T S H$ in cord serum in non-RDS and RDS infants*

\begin{tabular}{|c|c|c|c|c|c|c|c|c|c|c|c|c|}
\hline \multirow[b]{2}{*}{ Gestational age } & \multirow[b]{2}{*}{$n$} & \multicolumn{2}{|c|}{$\mathrm{BW}$} & \multicolumn{2}{|c|}{ GA } & \multicolumn{2}{|c|}{$\log T g$} & \multirow{2}{*}{$\begin{array}{c}\text { Geometric } \\
\text { mean } \mathrm{Tg}\end{array}$} & \multirow{2}{*}{$\begin{array}{c}\text { Estimated } \\
\log \mathrm{Tg}\end{array}$} & \multicolumn{2}{|c|}{ Log TSH } & \multirow{2}{*}{$\begin{array}{c}\text { Geometric } \\
\text { mean } \\
\text { TSH }\end{array}$} \\
\hline & & Mean & $\mathrm{SD}$ & Mean & $\mathrm{SD}$ & Mean & $\mathrm{SD}$ & & & Mean & $\mathrm{SD}$ & \\
\hline \multicolumn{13}{|l|}{ Non-RDS infants } \\
\hline $25-26-27$ & 4 & \multicolumn{2}{|c|}{$829 \pm 167$} & \multicolumn{2}{|c|}{$25.8 \pm 1.0$} & \multicolumn{2}{|c|}{$2.01 \pm 0.23$} & 102 & 2.19 & \multicolumn{2}{|c|}{$0.85 \pm 0.15$} & 7.1 \\
\hline $28-29-30$ & 19 & \multicolumn{2}{|c|}{$1392 \pm 256$} & \multicolumn{2}{|c|}{$29.0 \pm 0.7$} & \multicolumn{2}{|c|}{$2.18 \pm 0.34$} & 153 & 2.17 & \multicolumn{2}{|c|}{$0.86 \pm 0.25$} & 7.2 \\
\hline $31-32-33$ & 23 & \multicolumn{2}{|c|}{$1636 \pm 363$} & \multicolumn{2}{|c|}{$32.0 \pm 0.8$} & \multicolumn{2}{|c|}{$2.16 \pm 0.29$} & 143 & 2.12 & \multicolumn{2}{|c|}{$0.89 \pm 0.36$} & 7.7 \\
\hline $34-35-36$ & 47 & \multicolumn{2}{|c|}{$2251 \pm 439$} & \multicolumn{2}{|c|}{$35.0 \pm 0.9$} & \multicolumn{2}{|c|}{$2.11 \pm 0.22$} & 129 & 2.12 & \multicolumn{2}{|c|}{$0.88 \pm 0.29$} & 7.6 \\
\hline $37-38-39-40$ & 24 & \multicolumn{2}{|c|}{$2094 \pm 405$} & \multicolumn{2}{|c|}{$37.4 \pm 0.9$} & \multicolumn{2}{|c|}{$1.97 \pm 0.22$} & 93 & 2.02 & \multicolumn{2}{|c|}{$0.94 \pm 0.29$} & 8.7 \\
\hline \multicolumn{13}{|l|}{ RDS infants } \\
\hline $25-26-27$ & 4 & \multicolumn{2}{|c|}{$1040 \pm 225$} & \multicolumn{2}{|c|}{$26.3 \pm 0.9$} & \multicolumn{2}{|c|}{$1.95 \pm 0.20$} & 89 & 2.15 & \multicolumn{2}{|c|}{$0.55 \pm 0.44$} & 3.6 \\
\hline $28-29-30$ & 19 & \multirow{2}{*}{\multicolumn{2}{|c|}{$\begin{array}{l}1284 \pm 169 \\
1654+508\end{array}$}} & \multirow{2}{*}{\multicolumn{2}{|c|}{$28.8 \pm 0.7$}} & $2.43 \pm$ & 0.34 & 269 & 2.33 & $0.70 \pm$ & 0.32 & 5.0 \\
\hline $31-32-33-34$ & 7 & & & & & $2.41 \pm$ & 0.41 & 257 & 2.53 & $1.01 \pm$ & 0.27 & 10.2 \\
\hline
\end{tabular}

* Infants were subdivided into groups of 3 or more wk of gestation. Estimated $\log \mathrm{Tg}$ repesents the $\mathrm{Tg}$ values computed from the regression equations 1) and 2) for mean BW and mean GA.

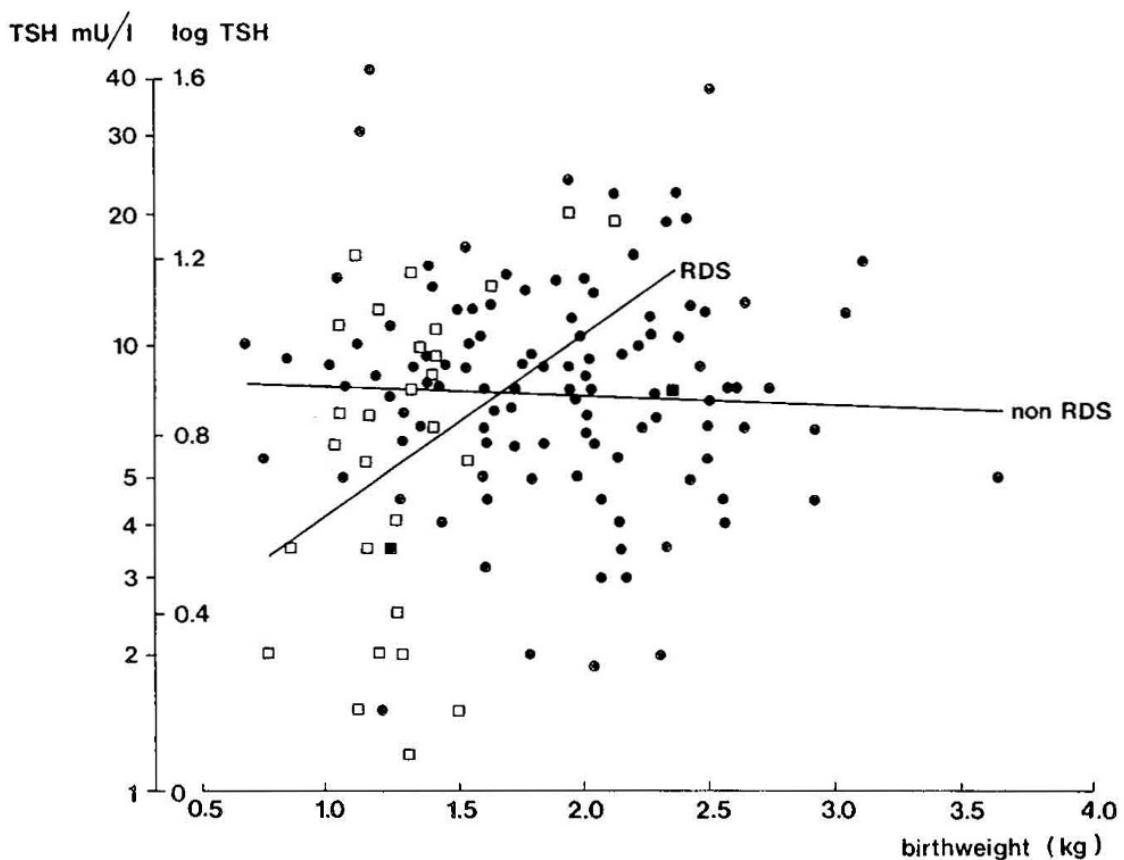

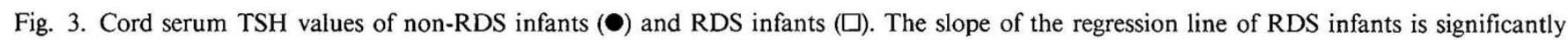
different from the slope of non-RDS infants ( $\square$ ): coinciding points of RDS and non-RDS infants.

RDS infants TSH values are not significantly dependent on BW. However, the slope of the regression line of RDS infants is significantly different from that of non-RDS infants $(p<0.05)$.

No correlation could be demonstrated between $\log$ TSH and $\log \mathrm{Tg}$ cord serum values either in non-RDS or in RDS infants ( $r=-0.04$ and 0.007 , respectively).

\section{DISCUSSION}

We have demonstrated that in RDS and non-RDS infants $\mathrm{Tg}$ cord serum levels are differently related to GA and BW. We found the Tg pattern of the "average" non-RDS infant (Fig. 1) to be comparable to the results reported by Ket et al. (2). This result is also in accordance with the decrease of $\mathrm{Tg}$ with chronological age in childhood (20).

The mean data of the non-RDS infants less than $37 \mathrm{wk}$ of gestation appear to follow the line repesenting the "average" infant (see Table 2 and Fig. 1). These infants all have mean BW in accordance with the 50th percentile for their gestation age. The non-RDS infants older than $37 \mathrm{wk}$ of gestation in this study, however, appeared on the average to be small for date; therefore their mean $\mathrm{Tg}$ values fall below the broken line of Figure 1.
These values can be predicted almost exactly from the regression equation 1) (see also Table 2, estimated $\mathrm{Tg}$ ). This reflects the accurate description of the data by this model.

With the exception of the early gestation ages, $\mathrm{Tg}$ levels found in RDS infants are significantly higher than in non-RDS infants. In non-RDS infants we found an increase of $\mathrm{Tg}$ cord serum levels with increasing BW when GA is constant. This appears to be in contrast with the data of Penny et al. (21). In their analysis groups were used composed of infants whose gestation age differed by three or more weeks. Therefore their findings reflect the combined effect of $\mathrm{GA}$ and $\mathrm{BW}$ on Tg cord serum levels. However, our statistical method analyzes the individual effects of BW and GA and gives a more accurate description. On the other hand, their results are consistent with the decrease of $\mathrm{Tg}$ in the "average" non-RDS infant found in our study.

$\mathrm{Tg}$ cord serum levels reported herein are in a similar range as reported by others $(6,22,23)$. On the other hand Black et al. (24) reported lower values, ranging from $30-40 \mathrm{ng} / \mathrm{ml}$ in both term and preterm infants. Moreover these authors found no difference between ill and healthy preterm infants.

A new finding is that RDS infants show higher Tg cord serum levels than non-RDS infants. Although in RDS infants both TSH 
and $\mathrm{Tg}$ levels appear to increase with increasing BW (Fig. 2 and 3 ), no correlation between $\mathrm{Tg}$ and $\mathrm{TSH}$ levels could be demonstrated. In non-RDS infants TSH shows no dependence on either GA or BW, as was also found by others (5). In the non-RDS infants we could not demonstrate a correlation between $\mathrm{Tg}$ and TSH either. These findings are in agreement with other studies $(2,6)$, but are in contrast with those of Penny et al. (21) in newborns. Moreover Roti et al. (25) could not demonstrate an increase of $\mathrm{Tg}$ cord serum levels in term infants after endogenous TSH stimulation caused by maternal administration of thyrotropin-releasing hormone.

None of the investigated perinatal factors which may stimulate or suppress maturation could be shown to influence Tg and TSH cord serum levels significantly.

We demonstrated a difference in $\mathrm{Tg}$ cord serum levels between RDS and non-RDS infants. We hypothesize that in addition to a given level of TSH stimulation, organ immaturity may be responsible for the high $\mathrm{Tg}$ cord serum values, especially in RDS infants; an enhanced permeability of the thyroid gland, e.g. caused by narrow tight junctions (26), and/or a delayed degradation of $\mathrm{Tg}$ by the liver may be involved.

Acknowledgments. The authors thank Dr. J. G. Koppe, who provided the opportunity to collect the material; Mrs. H. Bikker for $\mathrm{Tg}$ determinations, and Dr. E. Endert and the technicians of the laboratory of Endocrinology for TSH determinations, A. A. M. Hart for statistical supervision, Dr. M. H. Gons for fruitful discussions, and Mrs. S. Y. Majoor for secretarial assistance.

\section{REFERENCES}

1. Van Herle AJ, Uller RP, Brown J 1973 Radioimmunoassay for measurement of thyroglobulin in human serum. J Clin Invest 52:1320-1327

2. Ket JL, De Vijlder JJM, Bikker H, Gons MH, Tegelaers WHH 1981 Serum thyroglobulin levels: the physiologic decrease in infancy and the absence in athyroidism. J Clin Endocrinol Metab 53:1301-1303

3. Van Herle AJ, Vassart G, Dumont J 1979 Control of thyroglobulin synthesis and secretion (second of two parts). N Engl J Med 301:307-314

4. Oddie TH, Fisher DA, Bernard B, Lam RW 1977 Thyroid function at birth in infants of 30 to 45 weeks' gestation. J Pediatr 90:803-806

5. Klein AH, Oddie TH, Parslow M, Foley TP Jr, Fisher DA 1982 Developmental changes in pituitary-thyroid function in the human fetus and newborn. Early Hum Dev 6:321

6. De Nayer Ph, Cornette $\mathrm{C}$, Vanderschueren $\mathrm{M}$, Eggermont $\mathrm{E}$, De Vlieger $\mathrm{H}$ Jaecken J, Beckers C 1984 Serum thyroglobulin levels in preterm neonates. Clin Endocrinol 21:149-153

7. Redding RA, Douglas WHJ, Stein M 1972 Thyroid hormone influence upon lung surfactant metabolism. Science 175:994-996

8. Wu B, Kikkawa Y, Orzalesi MM, Motoyama EK, Kaibara M, Ziga SCJ, Cook CD 1973 The effect of thyronine on the maturation fetal rabbit lungs. Biol Neonate 22:161-168

9. Fisher DA, Dussault JH, Sack J, Chopra IJ 1977 Ontogenesis of hypothalamic pituitary-thyroid function and metabolism in man, sheep, and rat. Recent Prog Hormone Res 33:59-116

10. Redding RA, Pereira $C 1974$ Thyroid function in respiratory distress syndrome (RDS) of the newborn. Pediatrics 54:423-428

11. Cuestas RA, Engel RR 1979 Thyroid function in preterm infants with respiratory distress syndrome. J Pediatr 94:643-646

12. Abassi V, Merchant K, Abramson D 1977 Postnatal triiodothyronine concentrations in healthy preterm infants and in infants with respiratory distress syndrome. Pediatr Res 11:802-804

13. Dubowitz LMS, Dubowitz V, Goldberg C 1970 Clinical assessment of gestational age in the newborn infant. J Pediatr 77:1-10
14. Usher R 1961 The respiratory distress syndrome of prematurity, clinical and therapeutic aspects. Pediatr Clin N Am 8:525-538

15. Greenwood FA, Hunter WM, Glover JS 1963 The preparation of I labeled growth hormone of high specific radioactivity. Biochem J 89:114-123

16. Odell WD, Wilber JF, Paul WE 1965 Radioimmunoassay of thyrotropin in human serum. J Clin Endocrinol Metab 25:1179-1188

17. Draper N, Smith H 1981 Applied regression analysis, 2nd ed. John Wiley and Sons, New York, 1981

18. Snedecor GW, Cochran WG 1980 Correlation. In: Statistical Methods, 2nd ed. The Iowa State University Press, Ames, IA, pp 175-191

19. Kloosterman GJ 1970 On intrauterine growth. Int J Gynaecol Obstet 6:895

20. Penny R, Spencer CA, Frasier SD, Nicoloff JT 1983 Thyroid-stimulating hormone and thyroglobulin levels decrease with chronological age in children and adolescents. J Clin Endocrinol Metab 56:177-180

21. Penny R, Spencer CA, Frasier SD, Nicoloff JT 1984 Cord serum thyroidstimulating hormone and thyroglobulin levels decline with increasing birthweight in newborns. J Clin Endocrinol Metab 59:979-985

22. Osotimehin B, Black EG, Hoffenberg R 1978 Thyroglobulin concentration in neonatal blood: a possible test for neonatal hypothyroidism. $\mathrm{Br}$ Med J 2:1467-1468

23. Von Reuss K, Wieland $\mathrm{OH} 1981$ Thyroglobulin estimation for differentiation of hypothyrodism in neonatal thyroid screening. Acta Paediatr Scand [Suppl] 290:7-8

24. Black EG, Bodden SJ, Hulse JA, Hoffenberg R 1982 Serum thyroglobulin in normal and hypothyroid neonates. Clin Endocrinol 16:267-274

25. Roti E, Gnudi A, Braverman LE, Robuschi G, Emanuele R, Bandini P, Benassi L, Pagliani A, Emerson CH 1981 Human cord blood concentrations of thyrotropin, thyroglobulin, and iodothyronines after maternal administration of thyrotropin-releasing hormone. J Clin Endocrinol Metab 53:813817

26. Van Uijen AJ, van Dijk JE, Koch CAM, de Vijlder JJM 1985 Freeze fracture morphology of thyroid tight junctions in goats with different thyrotropin stimulation. Endocrinology 117:114-118.

\section{APPENDIX}

The multiple linear regression model is expressed in the following equation:

$$
y=a+b_{1} x_{1}+b_{2} x_{2}+b_{3} x_{3}+\cdots+b_{n} x_{n}
$$

where $y=\log \mathrm{Tg}$ or $\log \mathrm{TSH}, \mathrm{x}_{1}$ is $\mathrm{BW}$ in $\mathrm{kg}, \mathrm{x}_{2}$ is GA in wk, $\mathrm{x}_{3}$ $\cdots \mathrm{x}_{\mathrm{n}}$ are the variables to be investigated (RDS and the perinatal factors), $a$ is the intercept and $b_{1} \cdots b_{n}$ are the regression coefficients of $x_{1} \cdots x_{n}$. Inference from the multiple linear regression model requires the population to be normally distributed; therefore the analysis was performed after logarithmic transformation of the Tg and TSH data. We entered $\mathrm{BW}$ and GA as permanent variables in the regression analysis to interpret the specific effect of the other variables. This was necessary because the occurrence of these other variables is dependent on $\mathrm{GA}$ and/or BW (e.g. tocolysis and betamethasome treatment were given only if pregnancy was less than $33 \mathrm{wk}$ and if no signs of intrauterine growth retardation were present). Thus in each regression analysis the effects of BW and GA were eliminated first. Then the other variables were inserted stepwise in the regression procedure to test their specific influence on $\mathrm{Tg}$ or TSH cord serum concentrations. The order of insertion was determined by using the $\mathrm{F}$ test to measure the relative importance of variables not yet in the equation. A variable was entered into the regression only at a significance level of $p<0.05$. After establishing the effects of other variables, the specific effect of BW and/ or GA was tested. 